\title{
CFD INVESTIGATION OF CABIN AIR FLOW AND FINDING OUT THE MOST EFFICIENT DUCT COMBINATIONS
}

\author{
Shamim Ibrahim ${ }^{1}$, Arun S Lal' ${ }^{2}$ RC Metha ${ }^{3}$ \\ ${ }^{1}$ Head of Department, Basilous Mathew II College of Engineering \\ ${ }^{2}$ Assistant Professor, Younus College of Engineering \& Technology \\ ${ }^{3}$ Scientist ISRO
}

\begin{abstract}
It is very important to study and analyze the air distribution and thermal effects of the conditioned air that is supplied to the cabin. This is because all the passengers should be comforted with the ac system. The ac system is one of the most popular features of the automobile industry. In this work, a numerical investigation is carried out using the commercial software ANSYS about the flow and thermal analysis of the cabin air circulation. We had created a $3 d$ model of the maruti 800 car using design modeler and it is analyzed using the FLUENT software. Contours of velocity and temperature distribution are studied in detail. Four different combinations like front vent, front and rear vent, front and rear side vent, front and rear top vent are created and analyzed. The best configuration is find out from the temperature and velocity analysis.
\end{abstract}

Keywords: CFD, Refrigeration, Car AC

\section{INTRODUCTION}

Almost all the automobiles availabe in the market are fitted with air-conditioning systems. The manufacturers focus clearly on the AC system for a wide variety of climates. As technology advances AC system is also adhering major advancements. Now the focus is on how to improve the cabin comfortness with minimal energy input. Manufactures are giving special attention to improve the efficiency of the AC system. This work is mainly focusing on the interior thermal analysis of the cabin. The placing of AC ducts is an important factor in maintaining a constant temperature through out the cabin. This can only be found out by using a computational method like CFD. Here we are using ANSYS FLUENT for the study. A standard hatch back car is considerd and its graphical model is created and analysed. The different combinations of placin the $\mathrm{AC}$ vents is analysed and the best combination is found out. CFD analysis is considered as an important tool in most of the automobile industries in design and analysis of both interior and external sections. The commercial CFD package available is very good when appropriate grid and scheme are used. The AC system is automobiles are very different from a room air conditioning system. Even though the region is too small the heat gain is more. This is mainly due to the radiation effects, convection and heat generation from passengers, seats and other parts.

There are advanced developments in Air Flow Management, each passenger is satisfied with his on individual temperature needs ${ }^{[1]}$. The importance of this work is that it focus on maintaining a constant temperature through out the cabin space. Localised cooling or Heating of cabin is another recent development in AC system development ${ }^{[2]}$.

\section{METHODOLOGY}

First the numerical scheme is validated for an experimental analysis. Here we had conducted an experiment on a car AC system and the velocity and temperature of the conditioned air is measured. Grid independent study is conducted and optimum number of elements is determined.

\section{GOVERNING EQUATIONS}

The Navier-Stokes equations are the basic governing equations for a viscous, heat conducting fluid. It is a vector equation obtained by applying Newton's Law of Motion to a fluid element and is also called the momentum equation. It is supplemented by the mass conservation equation, also called continuity equation and the energy equation. Usually, the term Navier-Stokes equations is used to refer to all of these equations.

\section{CONTINUITY EQUATION}

$$
\boldsymbol{\nabla} \cdot \boldsymbol{u}=0 .
$$

MOMENTUM EQUATION

$$
\rho \frac{D u_{i}}{D t}=-\nabla p+\rho \mathbf{g}+\mu \nabla^{2} \mathbf{u}
$$

\section{NUMERICAL PROCEDURE}

First the numerical procedure is validated using and the optimum grid size is obtained. Then the model for CFD simulation is created using the SOLID EDGE software. This model is then exported to ANSYS design modeler. Here we are creating four different combinations of $\mathrm{AC}$ duct arrangements. Then we are evaluating the velocity 
distribution and temperature inside the cabin. We are following pressure based solution and k-epsilon turbulence model is assumed. The boundary conditions followed are velocity inlet for ac inlet duct and pressure outlet for recirculation duct. The below figures show the four different combinations of AC ventilation ducts.
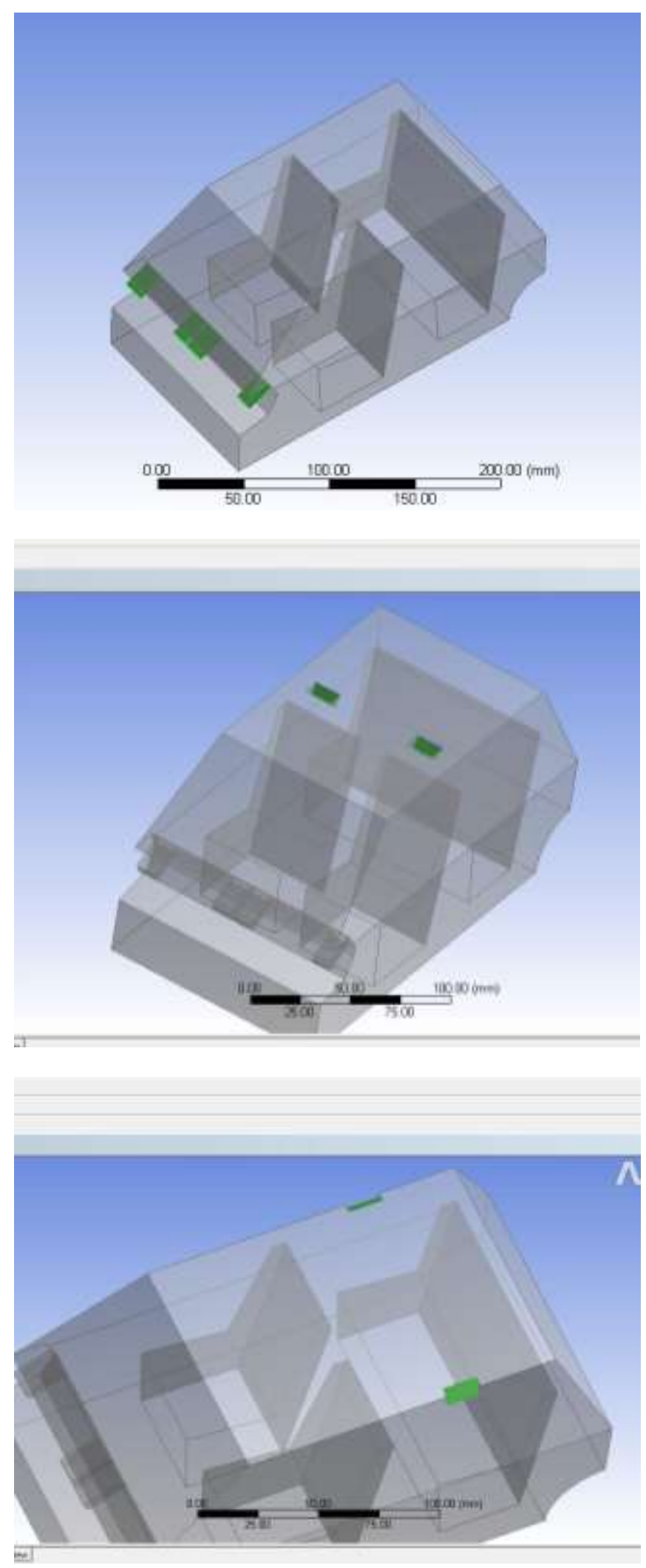

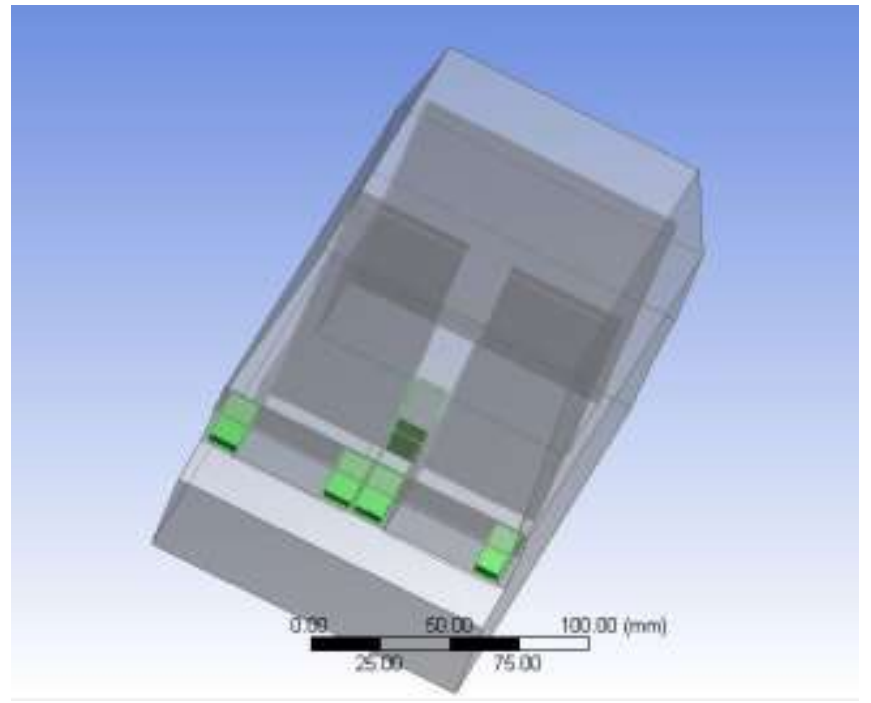

\section{RESULTS}

The problem is solved using ANSYS FLUENT and the results are studied. The below figure shows the temperature contours of a model.

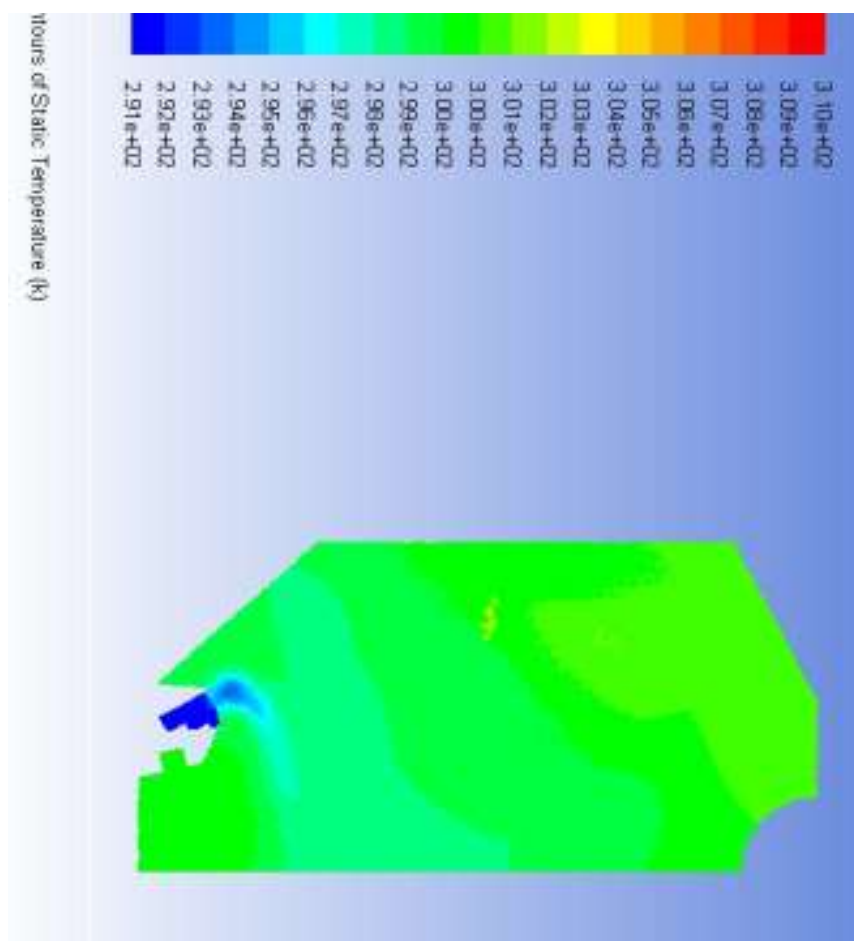

The values of inside cabin temperature and pressure are tabulated below. The four different combinations are considered and each of them are separately evaluated.

\begin{tabular}{|l|l|l|l|}
\hline & & cabin temp & pressure \\
\hline 1 & front vent only & 300.77051 & 101324.9 \\
\hline 2 & rear & 296.66516 & 101324.8 \\
\hline 3 & rear top side & 295.93311 & 101324.8 \\
\hline 4 & rear top face & 295.80493 & 101324.6 \\
\hline
\end{tabular}


The variation in cabin temperature with different positions of AC duct is plotted below. It shows that both rear top face and rear top side combinations had given better cooling than others.

There is no notable difference in the value of absolute pressure inside the cabin. The variation in inside pressure for different conditions is shown.

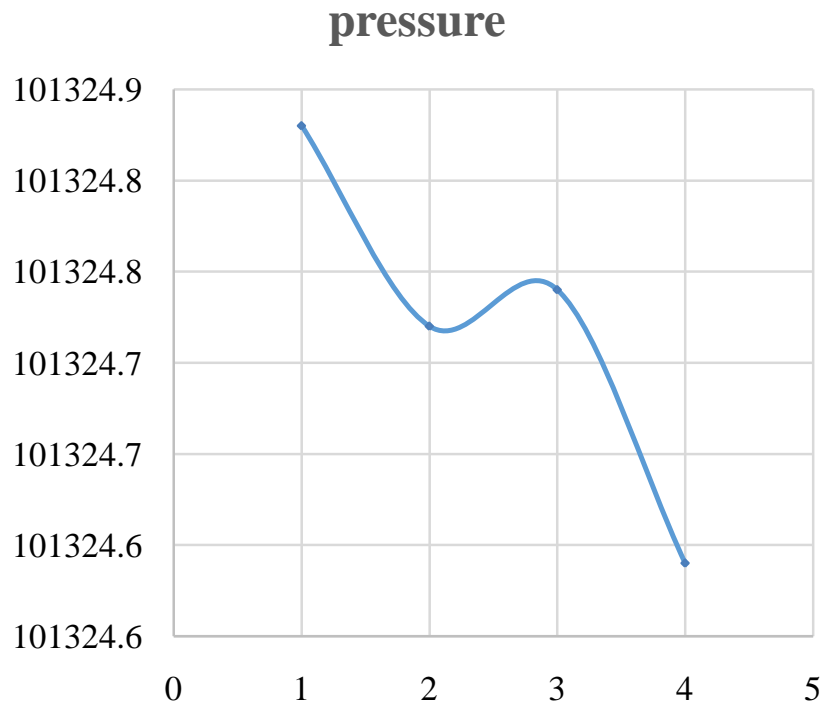

\section{CONCLUSION}

In this study we had created and analyzed four different AC vent combinations. The numerical model is created and solved in ansys fluent and the results are analyzed and studied. We can conclude that the cooling effect more when the $\mathrm{AC}$ duct is fitted in front side and also in the top rear side.

\section{REFERENCES}

[1]. Shen, F.Z., Backer, G.P., Swanson, D., HVAC Plenum Design Analysis, presented at SAE WorldCongress, 950113, 1995.

[2]. Werner, F., Frik, S., Optimization of an Automotive HVAC Module by Means of Computational Fluid Dynamics, presented at SAE World Congress, 950439, 1995.

[3]. Fluent Inc. User Guide, Fluent 6.3, 2006 